\title{
Preservation of organic matter in soils of a climo-biosequence in the main range of Peninsular Malaysia
}

\begin{abstract}
Limited information is available about factors of soil organic carbon (SOC) preservation in soils along a climo-biosequence. The objective of this study was to evaluate the role of soil texture and mineralogy on preservation of SOC in the topsoil and subsoil along a climobiosequence in the Main Range of Peninsular Malaysia. Soil samples from the A and Bhorizons of four representative soil profiles were subjected to particle-size fractionation and mineralogical analyses including X-ray diffraction and selective dissolution. The proportion of SOC in the 250-2000 $\mathrm{\varepsilon m}$ fraction (SOC associated with coarse sand) decreased while the proportion of SOC in the $<53 \mathrm{\varepsilon m}$ fraction (SOC associated with clay and silt) increased with depth. This reflected the importance of the fine mineral fractions of the soil matrix for SOC storage in the subsoil. Close relationships between the content of SOC in the $<53 \mathrm{\varepsilon m}$ fraction and the content of poorly crystalline $\mathrm{Fe}$ oxides [oxalate-extractable $\mathrm{Fe}$ (Feo) $\ddot{i}$ pyrophosphate-extractable Fe (Fep)] and poorly crystalline inorganic forms of Al [oxalateextractable Al (Alo) ï pyrophosphate-extractable Al (Alp)] in the B-horizon indicated the importance of poorly crystalline Fe oxides and poorly crystalline aluminosilicates for the preservation of SOC in the B-horizon. The increasing trend of Feo $\delta$ Fep and Alo $\delta$ Alp over elevation suggest that the importance of poorly crystalline $\mathrm{Fe}$ oxides and poorly crystalline aluminosilicates for the preservation of SOC in the B-horizon increased with increasing elevation. This study demonstrates that regardless of differences in climate and vegetation along the studied climo-biosequence, preservation of SOC in the subsoil depends on clay mineralogy.
\end{abstract}

Keyword: Particle-size fractionation; Poorly crystalline minerals; Soil organic matter; Soil texture 